\title{
Sexual Victimization, Health Status, and VA Healthcare Utilization Among Lesbian and Bisexual OEF/OIF Veterans
}

\author{
Kristin M. Mattocks, PhD, MPH ${ }^{1,2}$, Anne Sadler, PhD, RN $N^{3,4}$, Elizabeth M. Yano, PhD, MSPH $H^{5,6}$, \\ Erin E. Krebs, MD, MPH', , Laurie Zephyrin, MD, MPH, MBA', Cynthia Brandt, $M D, M P H^{10,17}$, \\ Rachel Kimerling, PhD ${ }^{12}$, Theo Sandfort, PhD ${ }^{13}$, Melissa E. Dichter, PhD, MSW 14 , \\ Jeffrey J. Weiss, $P h D, M S^{15}$, Jeroan Allison, MD, MS', and Sally Haskell, MD ${ }^{10,11^{\prime}}$
}

\begin{abstract}
IVA Central Western Massachusetts, Leeds, MA, USA; '2Department of Quantitative Health SciencesUniversity of Massachusetts Medical School, Worcester, MA, USA; ${ }^{3}$ Comprehensive Access \& Delivery Research and Evaluation (CADRE), Mental Health Service Linelowa City VA Health Care System, lowa City, IA, USA; 'Department of PsychiatryUniversity of lowa Hospitals and Clinics, lowa City, IA, USA; ${ }^{5}$ VA Greater Los Angeles HSR\&D Center of Excellence for the Study of Healthcare Provider Behavior, Sepulveda, CA, USA; ${ }^{\circ}$ UCLA School of Public Health, Los Angeles, CA, USA; ${ }^{7}$ Center for Chronic Disease Outcomes ResearchMinneapolis VA Health Care System, Minneapolis, MN, USA; ${ }^{8}$ University of Minnesota Medical School, Minneapolis, MN, USA; ${ }^{9}$ Department of Veterans Affairs, Washington, DC, USA; ${ }^{10}$ VA Connecticut Healthcare System, West Haven, CT, USA; ${ }^{11}$ Yale University School of Medicine, New Haven, CT, USA; ${ }^{2}$ National Center for PTSD, Center for Health Care EvaluationVA Palo Alto Health Care System, Menlo Park, CA, USA; ${ }^{13} \mathrm{HIV}$ Center for Clinical and Behavioral StudiesColumbia University, New York, NY, USA; ${ }^{14}$ Center for Health Equity Research and Promotion (CHERP)Philadelphia VA Medical Center, Philadelphia, PA, USA; ${ }^{15}$ Department of Medicine, Division of General Internal MedicineMount Sinai School of Medicine, New York, NY, USA.
\end{abstract}

BACKGROUND: Many lesbian and bisexual (LB) women veterans may have been targets of victimization in the military based on their gender and presumed sexual orientation, and yet little is known regarding the health or mental health of LB veterans, nor the degree to which they feel comfortable receiving care in the VA.

OBJECTIVE: The purpose of this study was to examine the prevalence of mental health and gender-specific conditions, VA healthcare satisfaction and trauma exposure among LB veterans receiving VA care compared with heterosexually-identified women veterans receiving.

DESIGN: Prospective cohort study of Operation Enduring Freedom/Operation Iraqi Freedom (OEF/OIF) women veterans at two large VA facilities.

PARTICIPANTS: Three hundred and sixty five women veterans that completed a baseline survey. Thirty-five veterans $(9.6 \%)$ identified as gay or lesbian (4.7\%), or bisexual (4.9\%).

MAIN MEASURES: Measures included sexual orientation, military sexual trauma, mental and gender-specific health diagnoses, and VA healthcare utilization and satisfaction.

KEY RESULTS: LB OEF/OIF veterans were significantly more likely to have experienced both military and childhood sexual trauma than heterosexual women (MST: $31 \%$ vs. $13 \%, p<.001$; childhood sexual trauma: $60 \%$ vs. $36 \%, p=.01)$, to be hazardous drinkers (32\% vs. $16 \%, p=.03$ ) and rate their current mental health as worse than before deployment (35\% vs. $16 \%, p<.001$ ). CONCLUSIONS: Many LB veterans have experienced sexual victimization, both within the military and as children, and struggle with substance abuse and poor mental health. Health care providers working with female Veterans should be aware of high rates of military sexual trauma and childhood abuse and refer women to appropriate VA treatment and support groups for sequelae of these experiences. Future research should focus on expanding this study to include a larger and more diverse sample of lesbian, gay, bisexual, and transgender veterans receiving care at VA facilities across the country.

KEY WORDS: lesbian; health services research; Veterans; women. J Gen Intern Med 28(Suppl 2):S604-8 DOI: $10.1007 /$ s1 1606-013-2357-9

(C) Society of General Internal Medicine 2013

\section{INTRODUCTION}

Many lesbian and bisexual (LB) veterans have been targets of victimization in the military based on their gender and presumed sexual orientation. Under Don't Ask, Don't Tell (DADT), thousands of LB women were discharged from military service, while countless others continued to serve in silence, and, as veterans, sought care from the Department of Veterans Affairs (VA). ${ }^{1,2}$ Prior research has shown that many LB veterans experience discrimination, rejection and/or poor care following disclosure of their sexuality to healthcare providers, ${ }^{3}$ and may engage in strategies to avoid conversations regarding sexual identity. These experiences may be particularly harmful for LB veterans returning from military deployments with substantial physical and mental health problems, ${ }^{4-7}$ and possibly compounded by lingering effects of targeted sexual assault and harassment experienced during military service based on perceived sexual orientation. ${ }^{8}$ Recent research $^{9}$ indicates that $15.1 \%$ of female OEF/OIF veterans report experiencing sexual trauma during 
military service. Given these healthcare needs among LB veterans, and the potential for underuse/care avoidance, understanding the healthcare needs of this population is crucial if the VA is to provide comprehensive care to all women veterans, regardless of sexual orientation.

\section{METHODS}

\section{Study Design}

The Women Veterans Cohort Study (WVCS) is an ongoing prospective cohort study involving male and female OEF/ OIF veterans receiving care at two VA facilities in the U.S, one in the northeast and one in the midwest ${ }^{8}$.

\section{Sample}

Letters describing the study were sent to 3,251 female OEF/OIF patients enrolled at each facility. Veterans expressing interest in the study contacted the research coordinator, read a study description, were consented and then, if enrolled, were screened for eligibility. Between July 2008 and October 2011, baseline surveys were completed by $11 \%$ of female veterans who were invited to participate $(n=365)$. For this study, data were obtained from two linked sources: participant surveys and VA electronic medical records.

\section{Participant Surveys}

Our analyses focused on questions that explored sexual orientation, physical and mental health status, combat and sexual trauma exposure, and satisfaction with VA care, using the measures below.

Sexual Orientation. Participants were asked to identify the sexual orientation category that best described them: heterosexual, gay or lesbian, bisexual, celibate or asexual, or not sure. The gay or lesbian and bisexual categories were combined for these analyses.

Post-Deployment Health Status. Post-deployment health was measured by asking participants to rate both their current physical and mental health as: much better than before deployment, slightly better than before deployment, about the same, slightly worse than before deployment, or much worse than before deployment.

Access to Care/Utilization. We asked participants whether they had private or public insurance and what type of private (e.g., employer-sponsored) or public (e.g., Medicare, Medicaid, Tricare) insurance they had. We also asked whether they had a regular provider, and whether that provider was a VA provider. Participants with a regular VA provider were asked if that provider was located in a Primary Care or Women's Health clinic.

Combat Trauma. Combat trauma was measured using the Combat Exposure Scale (CES), a seven-item self-report measure that has been shown to have a high degree of validity and reliability. ${ }^{10}$

Military Sexual Trauma. Sexual trauma during military service was assessed with the following two questions: "While you were in the military, did you receive uninvited and unwanted sexual attention, such as touching, cornering, pressure for sexual favors, or sexual remarks?", and "While you were in the military, did someone ever use force, or threat of force, to have sexual contact with you against your will?". Response categories included "yes" and "no".

Childhood Sexual Trauma. Childhood sexual trauma was assessed with specific questions about the presence and frequency of sexual abuse at different times in childhood, including childhood and adolescence prior to the age of $18{ }^{11}$ Response categories included: never, 1-2 times, 3-5 times, more than 5 times.

Smoking. Smoking status was ascertained by a question asking respondents about frequency of smoking cigarettes and data was recoded for respondents who smoked "everyday" and "some days" as current smokers, and those who smoked "not at all" as nonsmokers.

Hazardous Drinking. Hazardous drinking (drinking associated with possible harm) was defined as a score of eight or more on the Alcohol Use Disorders Identification Test (AUDIT). ${ }^{12}$

\section{VA Administrative Data Measures}

We used VA administrative records to assess 17 common women's health conditions (Appendix Table 5) for which both LB and heterosexual veterans might seek care. We used the Agency for Healthcare Research and Quality's (AHRQ) Clinical Classifications Software (CCS) framework to map ICD-9 codes to conditions; specific conditions were grouped into broad categories. ${ }^{13}$ A patient was considered to have one of the designated medical conditions if she had at least one ICD-9 code for that condition category assigned by a VA provider during the study period (2008-2011). We used the same methodology to assess mental health conditions (depression, bipolar disorder, post traumatic stress disorder [PTSD], and anxiety disorder). We derived a count of primary and mental health care visits during the study period from clinic stop codes in VA administrative files. 


\section{Analysis}

We used the $\chi^{2}$ test to compare the demographic, health care utilization, and clinical characteristics of LB and heterosexual veterans. Statistical analyses were performed using SAS version 9.1.3 (SAS, Inc., Cary, North Carolina).

\section{RESULTS}

Demographic characteristics of the study sample are presented in Table 1. Of the $365 \mathrm{OEF} / \mathrm{OIF}$ women veterans enrolled in the study, 35 women (9.6\%) identified as either gay or lesbian $(4.7 \%)$ or bisexual $(4.9 \%)$. Thirty women identified as asexual or celibate, and were excluded from the analysis. LB and heterosexual veterans did not differ significantly on demographic characteristics, including age, branch of service, race/ethnicity, or service component, though LB veterans were less likely to be married than heterosexual veterans. Most women veterans had private insurance, but LB women were significantly less likely to have government-sponsored insurance (e.g., Medicaid) (17\% vs. $32 \%, p=.03)$.

Overall, LB veterans were more likely to have been the victims of some form of childhood sexual abuse than heterosexual veterans $(60 \%$ vs. $36 \%, p<.001)$. LB veterans were significantly more likely to have experienced sexual abuse by an adult prior to their 13th birthday (46\% vs. $26 \%, p=.02$ ) and to have experienced sexual contact without consent between their 13th-18th birthdays (34\% vs. $17 \%, p=.02$ ) (Table 2).

Table 1. Demographic Characteristics of OEF/OIF Women Veterans $(n=335)$

\begin{tabular}{|c|c|c|c|}
\hline Characteristic & $\begin{array}{l}\text { LB } \\
\text { Veterans } \\
(n=35)\end{array}$ & $\begin{array}{l}\text { Heterosexual } \\
\text { Veterans } \\
(n=\mathbf{3 0 0})\end{array}$ & p \\
\hline \multicolumn{4}{|l|}{ Age (years) } \\
\hline$\leq 29$ & $55 \%$ & $56 \%$ & .85 \\
\hline$\geq 30$ & $46 \%$ & $44 \%$ & \\
\hline \multicolumn{4}{|l|}{ Race } \\
\hline White & $83 \%$ & $81 \%$ & .57 \\
\hline Black & $3 \%$ & $8 \%$ & \\
\hline Hispanic & $9 \%$ & $4 \%$ & \\
\hline Other & $3 \%$ & $2 \%$ & \\
\hline Unknown & $3 \%$ & $4 \%$ & \\
\hline \multicolumn{4}{|l|}{ Marital Status } \\
\hline Married & $20 \%$ & $35 \%$ & .04 \\
\hline Divorced & $6 \%$ & $13 \%$ & \\
\hline Not Married & $74 \%$ & $52 \%$ & \\
\hline \multicolumn{4}{|l|}{ Branch } \\
\hline Army & $66 \%$ & $69 \%$ & .38 \\
\hline Air Force & $20 \%$ & $17 \%$ & \\
\hline Marines & $9 \%$ & $3 \%$ & \\
\hline Navy & $6 \%$ & $10 \%$ & \\
\hline College education or higher & $57 \%$ & $46 \%$ & .20 \\
\hline $\begin{array}{l}50 \mathrm{~K} / \text { year or less in personal } \\
\text { income }\end{array}$ & $71 \%$ & $70 \%$ & .83 \\
\hline Private health insurance & $55 \%$ & $69 \%$ & .14 \\
\hline $\begin{array}{l}\text { Government-sponsored health } \\
\text { insurance (Medicaid, Medicare, } \\
\text { TRICARE) }\end{array}$ & $17 \%$ & $36 \%$ & .02 \\
\hline Service-connected disability & $57 \%$ & $56 \%$ & .89 \\
\hline $\begin{array}{l}\text { VA user (at least } 1 \text { primary care } \\
\text { or mental health visit in VA) }\end{array}$ & $86 \%$ & $87 \%$ & .92 \\
\hline
\end{tabular}

Fifty percent of the LB veterans and $35 \%$ of the heterosexual veterans had a diagnosed mental health condition of PTSD, anxiety disorder, depression, or bipolar disorder ( $p=$ $0.10)$ (Table 3). Since return from deployment, LB veterans were more likely than heterosexual veterans to rate their current mental health as worse than before deployment (35\% vs. $16 \%, p<.001)$, but there were no differences in postdeployment physical health ratings. LB veterans were more likely to be current smokers ( $43 \%$ vs. $23 \%, p=.008$ ) and hazardous drinkers (32\% vs. $16 \%, p=.03$ ) than heterosexual veterans. There were no statistically significant differences in diagnosed women's health conditions between the two groups.

Differences in experiences with and perceptions of VA healthcare are in Table 4. LB veterans were more likely to use VA providers for their healthcare than heterosexual veterans ( $31 \%$ vs. $14 \%, p=.01$ ), and were more likely to plan to use the VA in the future ( $100 \%$ vs. $88 \%, p=.03)$. There were no statistically significant differences between the two groups in perceptions of VA quality, availability of services, or ability to treat women veterans, although LB rated the latter two criteria lower than heterosexual veterans.

\section{DISCUSSION}

This is one of the first studies to examine health conditions and healthcare utilization among LB women veterans in VA care. In our study, LB veterans had

Table 2. Combat and Military/Childhood Sexual Trauma $(n=335)$

\begin{tabular}{|c|c|c|c|}
\hline & $\begin{array}{l}\text { LB } \\
\text { Veterans } \\
(n=35)\end{array}$ & $\begin{array}{l}\text { Heterosexual } \\
\text { Veterans } \\
(n=300)\end{array}$ & p \\
\hline \multicolumn{4}{|l|}{ Childhood sexual abuse } \\
\hline $\begin{array}{l}\text { Sexual abuse by adult } \\
\text { prior to } 13 \text { th birthday }\end{array}$ & $46 \%$ & $26 \%$ & .02 \\
\hline $\begin{array}{l}\text { Sexual abuse by anybody } \\
\text { prior to } 13 \text { th birthday }\end{array}$ & $31 \%$ & $19 \%$ & .08 \\
\hline $\begin{array}{l}\text { Sexual contact without } \\
\text { consent prior to } 18 \text { th } \\
\text { birthday }\end{array}$ & $34 \%$ & $17 \%$ & .02 \\
\hline $\begin{array}{l}\text { Any childhood sexual } \\
\text { assault }\end{array}$ & $60 \%$ & $36 \%$ & .01 \\
\hline \multicolumn{4}{|l|}{ Combat Trauma Exposure (CES) } \\
\hline Light & $49 \%$ & $57 \%$ & .74 \\
\hline Light to Moderate & $26 \%$ & $21 \%$ & \\
\hline Moderate & $11 \%$ & $14 \%$ & \\
\hline Moderate to Heavy & $11 \%$ & $7 \%$ & \\
\hline Heavy & $3 \%$ & $2 \%$ & \\
\hline \multicolumn{4}{|l|}{ Military sexual trauma } \\
\hline $\begin{array}{l}\text { Received uninvited } \\
\text { sexual attention during } \\
\text { military service } \\
\text { (touching, pressure, } \\
\text { remarks) }\end{array}$ & $60 \%$ & $49 \%$ & .20 \\
\hline $\begin{array}{l}\text { Experienced force or threat } \\
\text { for sexual contact during } \\
\text { military service }\end{array}$ & $31 \%$ & $13 \%$ & $<.001$ \\
\hline $\begin{array}{l}\text { Forcible sexual contact during } \\
\text { military and prior childhood } \\
\text { sexual abuse }\end{array}$ & $23 \%$ & $7 \%$ & $<.001$ \\
\hline
\end{tabular}


Table 3. Health Conditions Among LB and Heterosexual Veterans $(n=335)$

\begin{tabular}{|c|c|c|c|}
\hline & $\begin{array}{l}\text { LB Veterans } \\
(n=35)\end{array}$ & $\begin{array}{l}\text { Heterosexual } \\
\text { Veterans } \\
(n=300)\end{array}$ & $\mathbf{p}$ \\
\hline \multicolumn{4}{|c|}{ Mental health conditions } \\
\hline Bipolar disorder & $10 \%$ & $2 \%$ & .04 \\
\hline Anxiety disorder & $27 \%$ & $16 \%$ & .07 \\
\hline Major depression & $20 \%$ & $11 \%$ & .08 \\
\hline PTSD & $30 \%$ & $25 \%$ & .14 \\
\hline $\begin{array}{l}\text { Any mental health } \\
\text { condition }\end{array}$ & $50 \%$ & $35 \%$ & .10 \\
\hline \multicolumn{4}{|c|}{ Women's health conditions } \\
\hline Menstrual disorders & $10 \%$ & $14 \%$ & .19 \\
\hline $\begin{array}{l}\text { Female genital } \\
\text { disorders }\end{array}$ & $20 \%$ & $12 \%$ & .11 \\
\hline Vaginitis & $3 \%$ & $9 \%$ & .20 \\
\hline $\begin{array}{l}\text { Cervical dysplasia/ } \\
\text { ACSUS }\end{array}$ & $13 \%$ & $17 \%$ & .19 \\
\hline Pregnancy & $7 \%$ & $8 \%$ & .29 \\
\hline $\begin{array}{l}\text { Benign breast } \\
\text { conditions }\end{array}$ & $7 \%$ & $11 \%$ & .46 \\
\hline Ovarian cyst & $7 \%$ & $2 \%$ & .13 \\
\hline $\begin{array}{l}\text { Benign gynecologic } \\
\text { neoplasms }\end{array}$ & $3 \%$ & $4 \%$ & .38 \\
\hline $\begin{array}{l}\text { Menopausal } \\
\text { problems }\end{array}$ & $10 \%$ & $4 \%$ & .10 \\
\hline Infertility & $0 \%$ & $2 \%$ & .66 \\
\hline Sexual dysfunction & $0 \%$ & $1 \%$ & .90 \\
\hline Cervical cancer & $0 \%$ & $1 \%$ & .90 \\
\hline Osteoporosis & $0 \%$ & $1 \%$ & .90 \\
\hline Breast cancer & $0 \%$ & $0 \%$ & - \\
\hline Ovarian cancer & $0 \%$ & $0 \%$ & - \\
\hline $\begin{array}{l}\text { Female genital } \\
\text { cancer }\end{array}$ & $0 \%$ & $0 \%$ & - \\
\hline Uterine cancer & $0 \%$ & $0 \%$ & - \\
\hline $\begin{array}{l}\text { Rates current } \\
\text { physical } \\
\text { health as much } \\
\text { worse } \\
\text { than before } \\
\text { deployment }\end{array}$ & $17 \%$ & $17 \%$ & .97 \\
\hline $\begin{array}{l}\text { Rates current mental } \\
\text { health as much } \\
\text { worse } \\
\text { than before } \\
\text { deployment }\end{array}$ & $35 \%$ & $16 \%$ & $<.001$ \\
\hline & $43 \%$ & $23 \%$ & .01 \\
\hline $\begin{array}{l}\text { Alcohol disorder } \\
\text { (AUDIT) }\end{array}$ & $31 \%$ & $16 \%$ & .03 \\
\hline
\end{tabular}

higher rates of mental health problems, smoking, and poorer self-rated mental health. As echoed in a recent study, ${ }^{14}$ a striking finding was that $\mathrm{LB}$ veterans had experienced significantly higher rates of military sexual trauma than heterosexual veterans, and had higher rates of hazardous drinking, both consistent with other studies showing a high correlation between childhood sexual abuse and adult substance abuse disorder among lesbian women. ${ }^{15,16}$ Prior studies have noted high rates of antigay harassment in the military, ranging from verbal abuse to physical abuse to death threats, as well as sexual victimization, particularly among lesbianidentified service members. ${ }^{17}$ Universal screening for military service-related sexual trauma has been implemented within VA and has increased rates of mental health treatment. ${ }^{18}$ Health care providers working with female veterans should also be aware of high rates of combat exposure and childhood abuse and refer women to appropriate VA treatment and support groups for sequelae of these experiences.

This study has several limitations. Though only 35 veterans identified as gay, lesbian or bisexual, this selfreport represents $10 \%$ of our OEF/OIF survey cohort, which is slightly higher than population estimates of lesbians in the military ${ }^{2}$. Furthermore, because women veterans could enroll in the cohort study between 2008 and 2011, and Don't Ask Don't Tell hadn't yet been repealed, there is a possibility that the number of women identifying as LB in the study is an underestimate of the true population of women who self-identify as LB. In addition, we do not have data on the rates of mental health and substance use disorders of the veterans studied at the time they entered service. Elevated rates of mental health and substance use disorders may have placed them at increased risk for military sexual trauma. Other limitations of this study include that the original study focused on broad issues affecting all OEF/OIF women veterans and did not include a comprehensive assessment specific to LB veterans as an underserved population, nor any type of examination regarding the degree to which LB veterans may have felt marginalized or discriminated against in healthcare. Finally, we chose to combine the gay/lesbian category with the bisexual category for these analyses, which could have led to an overestimation or underestimation of associations reported in the analyses.

Very little research on the health and health care needs of LB veterans has been published to date. Research in non-veteran populations has demonstrated that LB persons often fear negative consequences of disclosing their sexual orientation

Table 4. VA Healthcare Utilization, Satisfaction, and Perceptions of Quality

\begin{tabular}{|c|c|c|c|}
\hline & $\begin{array}{l}\text { LB } \\
\text { Veterans } \\
(n=35)\end{array}$ & $\begin{array}{l}\text { Heterosexual } \\
\text { Veterans } \\
(n=300)\end{array}$ & $\mathbf{p}$ \\
\hline \multicolumn{4}{|c|}{ VA healthcare utilization and perception of quality } \\
\hline $\begin{array}{l}\text { Have only seen VA provider in } \\
\text { past year (no non-VA or } \\
\text { dual use) }\end{array}$ & $31 \%$ & $14 \%$ & .01 \\
\hline $\begin{array}{l}\text { VA Provider located in a Women's } \\
\text { Health Clinic }\end{array}$ & $24 \%$ & $34 \%$ & .41 \\
\hline $\begin{array}{l}\text { Plan to use VA in future as either } \\
\text { primary or secondary source } \\
\text { of care }\end{array}$ & $100 \%$ & $88 \%$ & .03 \\
\hline $\begin{array}{l}\text { Believes the VA provides quality } \\
\text { healthcare }\end{array}$ & $60 \%$ & $57 \%$ & .76 \\
\hline $\begin{array}{l}\text { Believes the VA has needed } \\
\text { health or mental health services }\end{array}$ & $51 \%$ & $59 \%$ & .36 \\
\hline $\begin{array}{l}\text { Believes VA physicians are } \\
\text { skilled at treating women }\end{array}$ & $31 \%$ & $44 \%$ & .16 \\
\hline $\begin{array}{l}\text { Feels welcome at the VA } \\
\text { Visits }\end{array}$ & $40 \%$ & $32 \%$ & .34 \\
\hline $\begin{array}{l}\text { Average number of primary care } \\
\text { visits in past year }\end{array}$ & 2.96 & 3.16 & .66 \\
\hline $\begin{array}{l}\text { Average number of mental health } \\
\text { visits in past year }\end{array}$ & 9.18 & 8.54 & .78 \\
\hline
\end{tabular}


to health care providers. These disclosure-related fears may have been amplified among veterans due to DADT; in our anecdotal experience, many veterans mistakenly believed DADT was a policy that VA shared with DOD. With the repeal of DADT, LB veterans may begin to feel more comfortable disclosing their sexuality to their VA healthcare providers without fear of reprisal. In turn, it is essential that VA healthcare providers create a healthcare environment free of assumed heterosexuality (e.g. not assuming that all female veterans require birth control for sexual activity) and ensure that they are knowledgeable about LB health issues.

Future research should focus on expanding this study to include a larger and more diverse sample of lesbian, gay, bisexual, and transgender veterans receiving care at VA facilities across the country. Questions regarding sexual orientation and behavior should also be included in all VA surveys to ensure that the needs of this population are being met across all areas of VA care.

\section{Acknowledgement:}

Contributors: The authors would like to acknowledge Cherry Sullivan, MPH and Tan Pham, MPH, for their help in preparing the document.

Funders: This material is based upon work supported by the Department of Veterans Affairs, Veterans Health Administration, Office of Research and Development. All authors had full access to all of the data in the study and take responsibility for the integrity of the data and the accuracy of the data analysis. The views expressed in this article are those of the authors and do not necessarily reflect the position or policy of the Department of Veterans Affairs or the United Stated Government. Dr. Yano's time was supported by a VA Health Services Research \& Development (HSR\&D) Service Senior Research Career Scientist Award (RCS \#05-195).

Conflict of Interest: The authors declare that they do not have a conflict of interest.

Corresponding Author: Kristin M. Mattocks, PhD, MPH; VA Central Western Massachusetts Healthcare System, 421 North Main Street, Leeds, MA 01053-9764, USA (e-mail: Kristin.mattocks@ va.gov).

\section{REFERENCES}

1. General Accounting Office. Defense force management: DoD's policy on homosexuality. (Document No. GAO/NSIAD-92-98). Washington, DC; 1992.

2. Gates G. Lesbian, gay, and bisexual men and women in the US military: Updated estimates. The Williams Institute, May 2010.

3. Seaver M, Freund $\mathbf{K}$, Wright L, Tjia J, Frayne S. Healthcare preferences among lesbians: a focus group analysis. J Womens Health. 2008; 17:215-225.

4. Haskell S, Mattocks K, Goulet J, et al. The burden of illness in the first year home: do male and female VA users differ in health conditions and healthcare utilization? Womens Health Issues. 2011;21:92-97.

5. Haskell S, Ning Y, Krebs E, Goulet J, Mattocks K, Kerns R, Brandt C. Prevalence of painful musculoskeletal conditions in female and male veterans in 7 years after return from deployment in Operation Enduring Freedom/Operation Iraqi Freedom. Clin J Pain. 2012;28(2):163-167.

6. Seal KH, Metzler TJ, Gima KS, Bertenthal D, Maguen S, Marmar CR. Trends and risk factors for mental health diagnoses among Iraq and Afghanistan Veterans using Department of Veterans Affairs Health Care, 2002-2008. Am J Public Health. 2009;99(9):16511658.

7. Mattocks K, Skanderson M, Goulet J, et al. Pregnancy and mental health among women veterans returning from Iraq and Afghanistan. J Womens Health. 2010;19(12):2159-2166.

8. Burks D. Lesbian, gay, and bisexual victimization in the military: an unintended consequence of 'Don't Ask, Don't Tell'? Am Psychol. 2011;66:604-613.

9. Kimerling R, Street A, Pavao J, et al. Military-related sexual trauma among Veterans Heatlh Administration patients returning from Iraq and Afghanistan. Am J Public Health. 2010;100(8):1409-1412.

10. Keane T, Fairbank J, Caddell J, Zimering R, Taylor K, Mora C. Clinical evaluation of a measure to assess combat exposure. Psychol Assess. 1989;1:53-55.

11. Kubany E, Haynes S, Kaplan A, et al. Development and preliminary validation of a brief broad-spectrum measure of trauma exposure: the Traumatic Life Events Questionnaire. Psychol Assess. 2000;12(2):210224.

12. Babor T, Ramon Dela Fuente J, Saunders J, Grant M. The alcohol use disorders identification test: Guidelines for use in primary health care. Geneva: World Health Organization; 1989.

13. Elixhauser A, Steiner C, Palmer L. Clinical Classifications Software (CCS), 2008. Accessed 1/17/2013: http://www.hcup-us.ahrq.gov/toolssoftware/ ccs/ccs.jsp.

14. Booth B, Davis T, Cheney A, Mengeling M, Torner J, Sadler A. Physical health status of female veterans: contributions of sex partnership and in-military rape. Psychosom Med. 2012;74:916-924.

15. Hughes T, Johnson T, Wilsnack S, Szalacha L. Childhood risk factors for alcohol abuse and psychological distress among adult lesbians. Child Abuse Negl. 2007;31:769-789.

16. Hughes T, Wilsnack S, Szalacha L, Johnson T, Bostwick W, Seymour $\mathbf{K}$, Kinnison $\mathbf{K}$. Age and racial/ethnic differences in drinking and drinking-related problems in a community sample of lesbians. J Stud Alcohol. 2006;67:579-590.

17. American Psychological Association Joint Divisional Task Force on Sexual Orientation and Military Service. Report of the Joint Divisional Task Force on sexual orientation and military service. Washington, DC: Accessed 1/17/2013: http://www.apa.org/pi/lgbt/resources/19-44taskforce-report.pdf ; 2009.

18. Kimerling R. Evaluation of universal screening for military-related sexual trauma. Psychiatr Serv. 2008;59:635-640.

\section{APPENDIX}

Table 5. List of all ICD-9 and V-Codes Used for Gender-Specific Diagnoses

\begin{tabular}{ll}
\hline \hline & ICD-9 Codes \\
\hline Uterine cancer & $179,182,233$ \\
Cervical Cancer & $180,233,795$ \\
Cancer of Ovary & 183 \\
Cancer, other Female genital organs & $181,183-184,233$ \\
Vaginitis, cervicitis, other pelvic & $112,614-616$ \\
$\quad$ inflammatory conditions & $625-626$ \\
Menstrual disorders & 622,795 \\
Cervical dysplasia and ASCUS & $256,619-626,629,795$ \\
Other female genital disorders & 628 \\
Female infertility & 256,627 \\
Menopausal disorders & $218-221,621-624$ \\
Benign gynecologic neoplasms & 620 \\
Ovarian cyst & $630-632,640-677,779,792$ \\
Pregnancy & $174-175,233$ \\
Breast cancer & $217,610-611,793$ \\
Benign breast conditions & $302,607,625$ \\
Sexual dysfunction & 733 \\
Osteoporosis &
\end{tabular}

